\title{
Information technology knowledge management in business
}

\author{
Zmiivska l. , Oboianska L. \\ Kharkiv Institute of Trade and Economics of Kyiv National University of Trade and Economics, Kharkiv, Ukraine
}

Received: $05.06 .2019 \quad$ Accepted: 19.07 .2019

\begin{abstract}
The paper considers modern information technologies of working with knowledge bases and describes the concepts of «Knowledge Management» and «Business Intellect». The classification of knowledge according to various categories of attributes is given. The principles of building knowledge management systems that are based on decision support algorithms and contain a database of models, a database, auxiliary and control programs are considered. The general architecture of the knowledge base management system is defined, which is multi-level and operates on the basis of data exchange between the data storage, ontology level and user application. Data exchange between these levels is carried out through the use of a query language and manipulation, as well as a data presentation language, on the basis of which two main directions of developing the architecture of knowledge management systems in business are defined: improving the functional parts of the user application and the direction that consists in manipulating data, orientation of the system to work with knowledge bases. Among the mechanisms for access to knowledge, there are mechanisms for searching, navigation and visualization, as well as the direct exchange of knowledge between users of the system. The list of components of the knowledge management system is given depending. A review of the categories of knowledge management software systems in business has been carried out and the functional purpose of each group of software products for managing knowledge bases has been described. The paper describes the existing categories of knowledge management software taking into account data access technologies, content management systems and the socially-oriented direction of development of knowledge management software in business with a description of the features of the software of each category. The work determined that the key role in the functioning of knowledge management systems belongs to the module of knowledge extraction, which can be represented in the form of frames, semantic networks and rules. The basic principles of building and using knowledge bases in solving key data mining tasks are included, including the task of finding interdependencies and associations, classifying objects and events, and predicting business process indicators through the use of a knowledge management system in business.
\end{abstract}

Key words: knowledge base, software, knowledge management system, data processing, data mining.

\section{Інформаційні технології управління знаннями у бізнесі}

\author{
Зміївська І. В., Обоянська Л. А.
}

Харківський торговельно-економічний інститут Київського національного торговельно-економічного університету, Харків, Україна

\begin{abstract}
Анотація. В роботі розглянуті сучасні інформаційні технології роботи з базами знань та надано характеристику понять «Управління знаннями» та «Інтелект бізнесу». Наведено класифікацію знань за різними категоріями ознак. Розглянуто принципи побудови систем управління знаннями, які засновані на алгоритмах підтримки прийняття рішень та містять базу моделей, базу даних, допоміжну та керуючу програми. Визначено загальну архітектуру системи управління базами знань, яка $є$ багаторівневою та функціонує на базі обміну даними між сховищем даних, рівнем онтології та додатком користувача. Обмін даними між зазначеними рівнями здійснюється шляхом використання мови запитів та маніпулювання, а також мови представлення даних, на підставі чого визначено два основні напрями розробки архітектури систем управління знаннями у бізнесі: вдосконалення функціональних частин додатку користувача та напрям, який полягає у маніпулюванні даними, що означає спрямованість системи на роботу з базами знань. Серед механізмів доступу до знань визначено механізми пошуку, навігації та візуалізації, а також безпосередній обмін знаннями між користувачами системи. Наведено перелік складових системи управління знаннями в
\end{abstract}

\footnotetext{
Corresponding Author: Zmiivska Iryna Vitaliivna. Tel. +38(067) 998 9078. irina.zmievska@gmail.com. Kharkiv Institute of Trade and Economics of Kyiv National University of Trade and Economics, prov. O. Jarosha, 8, Kharkiv, Kharkiv Region, Ukraine, 61045.

Відповідальний автор: Зміївська Ірина Віталіївна. +38(067) 998 9078. irina.zmievska@gmail.com. Харківський торговельно-економічний інститут Київського національного торговельно-економічного університету, пров. О. Яроша, 8, м. Харків, Харківської обл., Україна, 61045.
} 
залежності від області вирішуваних задач. Виконано огляд категорій програмного забезпечення систем управління базами знань у бізнесі та охарактеризовано функціональне призначення кожної групи програмних продуктів для управління базами знань. В роботі надано характеристику існуючих категорій програмного забезпечення управління знаннями 3 урахуванням технологій доступу до даних, системи управління контентом та соціально-орієнтованого напрямку розвитку програмного забезпечення управління знаннями у бізнесі з описом особливостей функціонування програмного забезпечення кожної категорії. В роботі визначено, що ключова роль при функціонуванні систем управління знаннями належить модулю вилучення знань, які можуть бути представлені у вигляді фрреймів, семантичних мереж та правил. Наведено основні принципи побудови та використання баз знань при вирішенні ключових задач інтелектуального аналізу даних, до яких належать задачі пошуку взаємозалежностей та асоціацій, класифікації об'єктів та подій, прогнозування показників бізнес-процесів через використання системи управління знаннями у бізнесі.

Ключові слова: база знань, програмне забезпечення, система управління знаннями, обробка даних, інтелектуальний аналіз даних.

\title{
Информационные технологии управления знаниями в бизнесе
}

\author{
Змиевская И. В., Обоянская Л. А.
}

Харьковский торгово-экономический институт Киевского национального торгово-экономического университета, Харьков, Украина

\begin{abstract}
Аннотация. В работе рассмотрены современные информационные технологии работы с базами знаний и охарактеризованы понятия «Управление знаниями» и «Интеллект бизнеса». Приведена классификация знаний по различным категориям признаков. Рассмотрены принципы построения систем управления знаниями, которые основаны на алгоритмах поддержки принятия решений и содержат базу моделей, базу данных, вспомогательную и управляющую программы. Определена общая архитектура системы управления базами знаний, которая является многоуровневой и функционирует на основе обмена данными между хранилищем данных, уровнем онтологии и приложением пользователя. Обмен данными между указанными уровнями осуществляется путем использования языка запросов и манипулирования, а также языка представления данных, на основании чего определены два основных направления разработки архитектуры систем управления знаниями в бизнесе: совершенствование функциональных частей приложения пользователя и направление, которое заключается в манипулировании данными, что означает направленность системы на работу с базами знаний. Среди механизмов доступа к знаниям определены механизмы поиска, навигации и визуализации, а также непосредственный обмен знаниями между пользователями системы. Приведен перечень составляющих системы управления знаниями в зависимости от области решаемых задач. Выполнен обзор категорий программного обеспечения систем управления базами знаний в бизнесе и охарактеризовано функциональное назначение каждой группы программных продуктов для управления базами знаний. В работе охарактеризованы существующие категории программного обеспечения управления знаниями с учетом технологий доступа к данным, системы управления контентом и социально-ориентированного направления развития программного обеспечения управления знаниями в бизнесе с описанием особенностей функционирования программного обеспечения каждой категории. В работе определено, что ключевая роль при функционировании систем управления знаниями принадлежит модулю извлечения знаний, которые могут быть представлены в виде фреймов, семантических сетей и правил. Приведены основные принципы построения и использования баз знаний при решении ключевых задач интеллектуального анализа данных, к которым относятся задачи поиска взаимозависимостей и ассоциаций, классификации объектов и событий, прогнозирование показателей бизнес-процессов при использовании системы управления знаниями в бизнесе.
\end{abstract}

Ключевые слова: база знаний, программное обеспечение, система управления знаниями, обработка данных, интеллектуальный анализ данных.

\section{Bcmyn}

В сучасних умовах досить значна кількість галузей потребують втручання з боку сфери інформаційних технологій для підвищення рівня конкурентоспроможності на ринку. Багато бізнеспроектів потребують використання методів управління знаннями (knowledge management) [1-5] та розкриття поняття «Інтелект бізнесу» (business intelligence) [1, 6-8], яке передбачає прогнозування та прийняття рішень на основі аналізу прикладних структурованих даних.

Управління знаннями представляє собою сукупність керуючих процесів для створення, розповсюдження, обробки і використання інформації всередині підприємства [1]. Системи управління знаннями - основа IT-інфраструктури різних компаній, оскільки ці системи дають можливість перетворювати велику бізнес-інформацію в ясні і корисні висновки. Збір, обслуговування та аналіз 
великих обсягів даних - це завдання, які вимагають великих затрат і адекватних організаційних рішень, а також подолання серйозних технічних труднощів [6-8].

Побудова бази знань базується на поняттях фрактів та евристики [3]. Факти - це добре відомі і описані обставини. До них відносяться також економічні категорії, відомі і описані закономірності. Евристики - знання, досвід, навички фахівців у відповідних предметних областях. Вони є об'єктом вивчення і впровадження в системах різного призначення.

Знання розділяються на декларативні та процедурні [5]. Декларативні знання є очевидними, в той час як процедурні - по суті $€$ алгоритмами перетворення декларативних знань, дій над ними. Розрізняють глибинні і поверхневі знання. Глибинні знання містять докладні відомості про структуру предметної області, закони поведінки структури в цілому і окремих її елементів, достовірні і повні відображення взаємозв'язків елементів структури тощо. Поверхневі знання стосуються лише зовнішніх властивостей і зв'язків з даним об'єктом. Існують також жорсткі та м'які знання [5]. Жорсткі знання відображають системи або об'єкти з чітко вираженими властивостями, зв'язками, поведінкою, які легко описуються якісними і кількісними ознаками, наприклад логіко-дедуктивною системою показників. М'які знання відображають відповідно системи і об'єкти, які важко піддаються опису або формалізації властивостями і зв'язками. Дають нечіткі, розмиті рішення з множиною рекомендацій [9-11].

Різні варіанти класифікації технологій управління знаннями наведено у роботах [12-15]. Згідно [16] інструментарій систем управління знаннями охоплює класи, які найбільш повно і цілісно характеризують область комплексу завдань управління знаннями у бізнесі.

Актуальність даної роботи полягає у необхідності вирішення проблеми щодо комплексного аналізу застосування програмного забезпечення управління знаннями у бізнесі та визначення особливостей організації інформаційних технологій, які використовуються у бізнес-процесах.

Мета роботи полягає у визначенні стратегії та інструментальних засобів управління знаннями, необхідних для підвищення якості та ефективності процесу управління знаннями у бізнесі.

\section{II Матеріал і методи дослідження}

Системи управління знаннями представляють комплекс програмних засобів, який включає бібліотеку різних алгоритмів підтримки рішень, базу моделей, базу даних, допоміжну і керуючу програми. Керуюча програма організовує на ПЕОМ процес прийняття рішень з урахуванням специфіки проблеми.

Структура систем управління знаннями залежить від вирішуваних завдань і може містити наступні компоненти:

- бази даних, сховища даних і баз знань;

- управління документообігом;

- підтримка спільної роботи з інформаційними ресурсами;

- автоматизовані вилучення знань з тексту;

- пошук в текстовій і структурованій інформації (в тому числі пошук за метаданими);

- автоматична класифікація та кластеризація документів;

- отримання знань від експертів;

- машинний переклад;

- автоматичне рефрерування і анотування;

- інтелектуальний аналіз даних;

- автоматичне розпізнавання образів;

- підтримка прийняття рішень;

- підтримка інноваційної діяльності (формування нових знань).

Для управління знаннями широкого поширення набувають програмні продукти компанії Gartner Group, які можна поділити на три основні категорії (рис. 1).

Створення баз знань в процесі діяльності підприємства викликано необхідністю використання набутого досвіду через обмін структурованими даними про бізнес-процеси. Для керування ринком знань використовуються спеціалізовані програмні інструменти, представлені інформаційними технологіями широкої галузі застосування. 


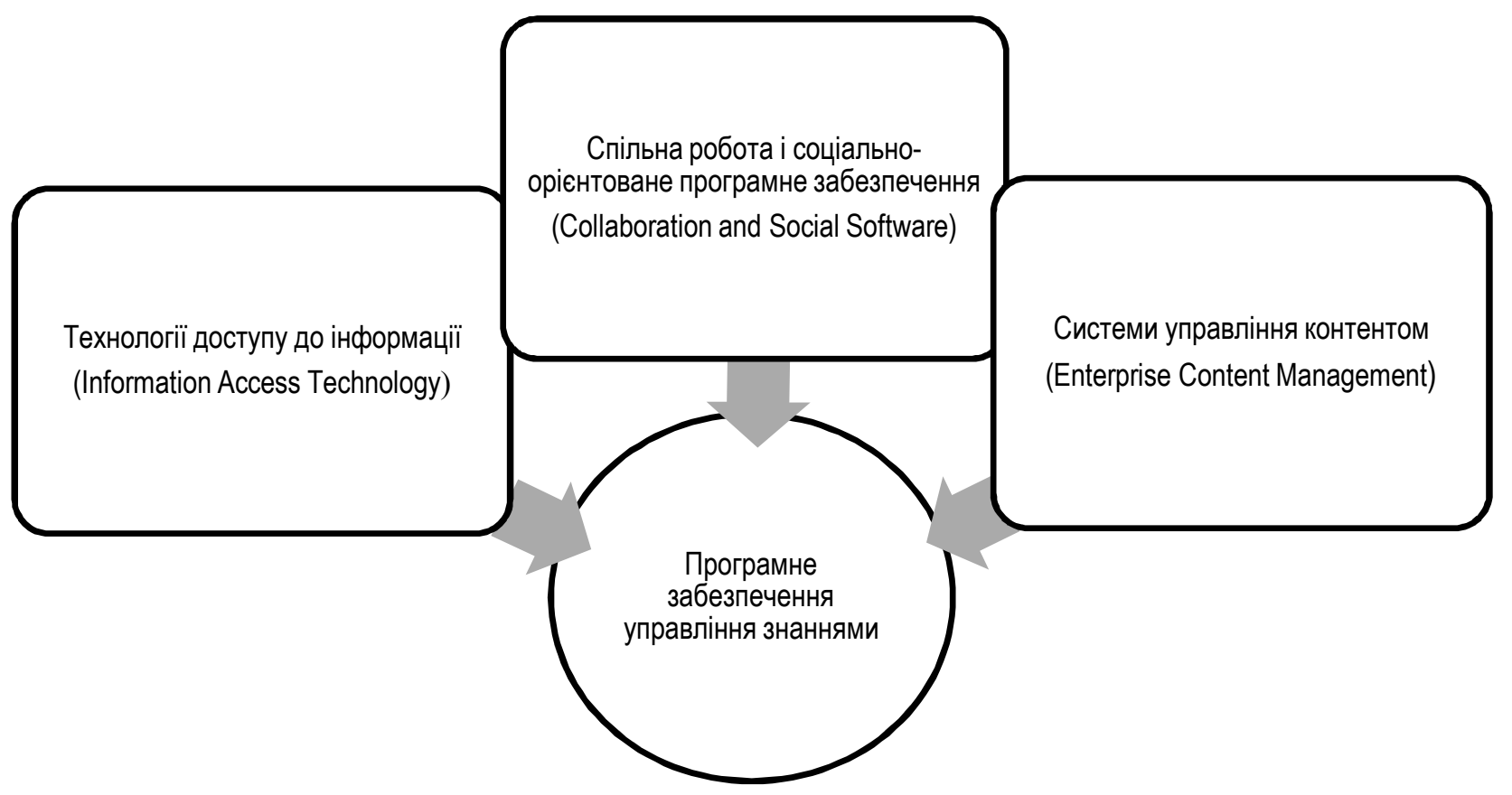

Рис. 1. Категорії програмного забезпечення управління знаннями

До категорії «Information Access Technology» відноситься пошук за ключовими словами, складні запити, пошук з використанням класифікації документів за групами. Деякі програми мають можливості автоматичного анотування будь-якого вхідного документу і побудови автоматичної класифікації за

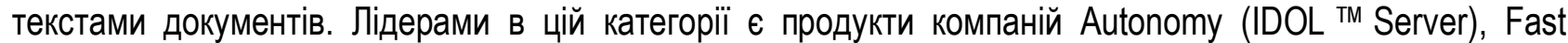
Search \& Transfer (FAST ESP, Convera RetrievalWare), Endeca, IBM.

Програмні продукти категорії «Collaboration and Social Software» підтримують комунікації і забезпечують єдину віртуальну робочу середу, спільну роботу з документами, робочі дошки, що створює можливості для організації спільної розробки документації в єдиному інформаційному просторі. Програми цієї категорії створюють персональні профрілі співробітників з вказанням особистих та професійних даних, а також каталоги експертів. Лідерами в цій групі $є$ продукти компаній BEA (BEA Aqualogic), SpikeSource (SuiteTwo), Socialtext (Socialtext), IBM i Microsoft.

Категорія «Enterprise Content Management» включає різні інструменти для гнучкої і надійної роботи 3 документами, наприклад, реєстрацію, управління версіями, безпеку, сканування та розпізнавання. Також до цієї групи відноситься створення архівів, наповнення, оновлення та структурування вмісту сайтів, організація взаємодії з відвідувачами сайтів. Лідерами в цій категорії $є$ продукти компаній IBM (Content Manager, Filenet P8), EMC (EMC Documentum), Opentext (Livelink ECM 10).

Окремо слід зазначити, що існує також група спеціалізованого програмного забезпечення, яке отримало назву Веб 2.0, головна особливість якого полягає у залученні користувачів до процесу формування та якісного змінення контенту інтернет-ресурсів. Загальну архітектуру багаторівневої системи управління знаннями наведено на рис. 2.

Рівень сховища забезпечує отримання знань з різних джерел структурованих і неструктурованих даних. Рівень онтології забезпечує використання програмних засобів автоматичного формування онтології, підтримки ручної розробки і редагування онтології, засобів злиття, об'єднання і оцінки якості онтологій. Проміжний рівень забезпечує зберігання онтологій і метаданих, управління версіями, доступом, передачу даних для взаємодії із зовнішніми системами і сховищами, обробку запитів і логічний висновок. 


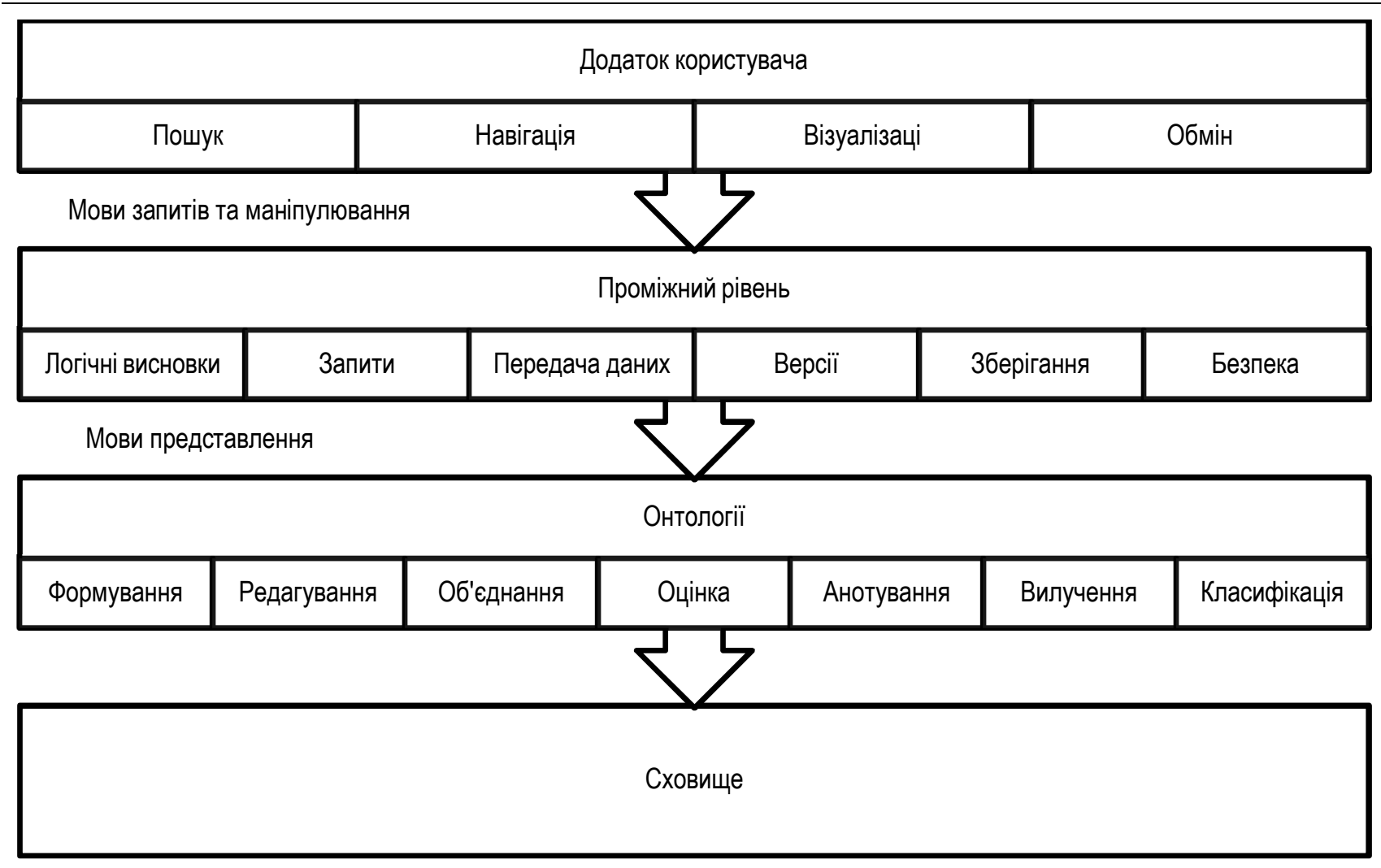

Рис. 2. Загальна архітектура системи управління знаннями

Користувацькі додатки надають користувачам доступ до знань, що знаходяться в системі. Доступ може здійснюватися за допомогою пошукового механізму, засобів навігації та візуалізації, а також шляхом безпосереднього обміну знаннями між користувачами. Взаємодія користувача додатків 3 проміжним рівнем здійснюється за допомогою мов запитів і маніпулювання даними.

\section{III Результати}

В залежності від цілей управління знаннями архітектура системи може бути спрямована на вдосконалення програмної реалізації функціональних частин додатку користувача (в цьому випадку мова йде про «портал знань») або на маніпулювання знаннями: отримання, вилучення, зберігання, інтеграцію, що свідчить про наявність стратегії роботи з базами знань.

Системи управління знаннями охоплюють класи, які найбільш повно і цілісно характеризують область комплексу завдань управління знаннями у бізнесі:

1. Аналіз наявної в компанії інформації.

2. Вилучення, структурування і формалізація знань (інженерія знань).

3. Обмін і використання знань.

4. Пошук інформації за запитом.

5. Організація зберігання.

6. Навчання.

7. Інтегровані системи обробки, що поєднують перераховані вище функції.

Важливою складовою частиною будь-якої бази знань $€$ модуль вилучення знань, основне призначення якого - представлення експертних знань, їх структурування у вигляді придатному для використання при управлінні бізнесом. До задач модуля відносять приведення правила до виду, що дозволяє застосувати це правило в процесі роботи. У найпростішому випадку в якості такого модуля може виступати звичайний редактор, який додає правила до файлу. У деяких системах вилучення знань здійснюється не одним, а кількома способами, наприклад, частина знань вилучається за допомогою програмних засобів, які аналізують граматику описання знань, що задає форму подання знань; інші знання можуть бути представлені графічно за допомогою спеціальних засобів, які дозволять 
сприймати графічні зображення і перевіряти їх на правильність; можливо формування знань, які самою системою не використовуються, а при необхідності можуть вводитися в діалоговому режимі. Загальними методами представлення знань є: правила, семантичні мережі, фрейми.

Існує два головних способи отримання знань. Перший - це «вилучення» знань з живого джерелаексперта, спеціаліста з метою їх ідентифікації та можливої формалізації, переміщення в базу знань і побудови на цій основі експертних систем, а також в інших цілях. Такий процес відносять до інженерії знань. Інший - це «видобуток» прихованих від користувача знань з даних, поміщених в різного роду комп'ютерні інфрормаційні системи, в тому числі бази даних різного призначення, інформаційні сховища. Цей процес називають Data mining - інтелектуальний аналіз даних.

\section{IV Обговорення}

Для обробки накопичених в різних джерелах і місцях збору та зберігання даних і виконання інтелектуального аналізу використовуються методи лінійної алгебри, класичного математичного аналізу, дискретної математики, багатовимірного статистичного аналізу. Традиційна математична статистика довгий час була основною методології аналізу даних. Однак базова концепція усереднення по вибірці часто призводить до операцій над фіктивними величинами. 3 цієї причини виникла ціла низка методів, які відносять до специфічних стосовно інтелектуального аналізу даних [3-5].

Інтелектуальний аналіз даних (IАД) - це процес підтримки прийняття рішень, заснований на пошуку в даних схованих закономірностей (шаблонів інформації) [9-11]. Вибір методу ІАД залежить від типу наявних даних і від того, яку інформацію необхідно отримати. Основними завданнями інтелектуального аналізу даних $€$ [12-16]:

- виявлення взаємозалежностей, причинно-наслідкових зв'язків, асоціацій і аналогій, визначення значень факторів часу, локалізація подій або явищ за місцем;

- класифікація подій і ситуацій, визначення профрілів різних фракторів;

- прогнозування ходу процесів, подій.

Вирішення задач інтелектуального аналізу даних виконується шляхом використання баз знань та спеціалізованого програмного забезпечення 3 реалізації інструментальних можливостей систем управління базами знань [15, 17-19].

\section{V Висновки}

У результаті проведеного дослідження можна зробити наступні висновки:

1. Інформаційні технології, які використовуються в управлінні знаннями, передбачають використання програмних засобів, що дозволяють підвищити матеріально-технологічний рівень представлення знань про діяльність підприємства та отримати додаткові потужні інноваційні ресурси.

2. Напрям функціональних можливостей використовуваного програмного забезпечення визначається особливостями бізнесу кожного підприємства та передбачає наявність спеціальних елементів автоматизації обробки даних та знань.

3. Проектування системи управління знаннями на програмному рівні вимагає інтеграції окремих програмних систем та модулів в єдине середовище, ядром якого є база знань підприємства.

Формування баз знань $є$ складним процесом, який в більшості випадків вимагає використання методів та засобів інтелектуального аналізу даних. В той же час вирішення багатьох задач управління бізнесом шляхом інтелектуального аналізу даних має в основі використання баз знань про керовані процеси.

\section{Бібліографрічні посилання}

1. Руденко М.В., Криворучко В.О. Управління знаннями як конкурентна перевага підприємства / Економіка та держава. 2016. № 4. C. 74-78.

2. Захарова Я.О., Захаров С.Є. Сутність, підходи та інструменти управління знаннями / Економіка будівництва і міського господарства. 2011. №2. С. 133-139.

3. Ramezan M. Examining the impact of knowledge management practices on knowledge based results / Journal of Knowledge-based Innovation in China. 2013. Vol. 3. Issue 2. PP. 106-118. 
4. Seleim Ahmed A.S. Understanding the knowledge management-intellectual capital relationship: a two way analysis / Journal of Intellectual Capital. 2011. Vol. 12. Issue 4. PP. 586-614.

5. Shu-hsien Liao, Chi-chuan Wu. The Relationship among Knowledge Management, Organizational Learning, and Organizational Performance / International Journal of Business and Management. 2009. Vol. 4. Issue 4. PP. 64-76.

6. Томах В.В. Сутність процесу управління знаннями підприємств промисловості / Проблеми економіки. 2014. № 2. С. $161-166$.

7. Щербаков О.В., Наришкін В.С. Система підтримки прийняття рішень як невід'ємна частина сучасного інформаційного забезпечення для управління бізнесом / Інформаційні технології в технічних системах. 2011. № 3. С. 93-96.

8. Бочуля Т.В. Організація інформаційної складової процесу управління в економічному просторі / Європейський вектор економічного розвитку. 2013. № 2. С. 32-43.

9. Sangjae Lee. An integrated view of knowledge management for performance / Journal of Knowledge Management. 2012. Vol. 16. Issue 2. PP. 183-203.

10. Ologbo Andrew C., Khalil Md Nor. Knowledge Management Processes and Firm Innovation Capability: A Theoretical Model / Asian Social Science. 2015. Vol. 11. No. 18. PP. 10-17.

11. Левикін В. М. Модель бази знань інформаційної системи процесного управління / Вісник НТУ "ХПІ" : зб. наук. пр. Сер. : Системний аналіз, управління та інформаційні технології. Харків : НТУ "ХПІ", 2017. № 28 (1250). С. 74-78.

12. Ologbo Andrew C., Khalil Md Nor. Knowledge Management: The Way to Organizational Competitive Advantage / Economics of Knowledge. 2015. Vol. 7. Issue 1. PP. 25-35.

13. Inkinen H. Review of empirical research on knowledge management practices and firm performance / Journal of Knowledge Management. 2016. Vol. 20. Issue 2. PP. 230-257.

14. Storey Veda C. II-YeolSongb Big data technologies and Management: What conceptual modeling can do / Data \& Knowledge Engineering. 2017. Vol. 108. PP. 50-67.

15. Massaro M., Dumay J., Garlatti A. Public sector knowledge management: a structured literature review / Journal of Knowledge Management. 2015. Vol. 19. Issue 3. PP. 530-558.

16. Paré G., Trudel M.-Cl., Jaana M., Kitsiou Sp. Synthesizing information systems knowledge: A typology of literature reviews / Information \& Management. 2015. Volume 52. Issue 2. PP. 183-199.

17. Brhel M., Meth H., Maedche A., Werder K. Exploring principles of user-centered agile software development: A literature review / Information and Software Technology. 2015. Volume 61. PP. 163-181.

18. Panetto H., Zdravkovic M., Jardim-Goncalves R., Romero D., Cecil J., Mezgár I. New perspectives for the future interoperable enterprise systems / Computers in Industry. 2016. Volume 79. PP. 47-63.

19. Рибалко Л.П. Застосування сучасних корпоративних інформаційних систем в управлінні підприємствами / Науковий вісник Херсонського державного університету : зб. наук. пр. Сер.: Економічні науки. Херсон, 2015. Вип. 15. С. 82-85.

\section{References}

1. Rudenko, M.V., Kryvoruchko, V.O. (2016). Upravlinnya znannyamy yak konkurentna perevaga pidpryemstva. Ekonomika ta derzhava, 4, 74-78. [in Ukrainian]

2. Zaharova, Ya.O., Zaharov, S.E. (2011). Sutnist', pidhody ta instrumenty upravlinnya znannyamu. Ekonomika budivnytstva I mis'kogo gospodarstva, 2, 133-139. [in Ukrainian]

3. Ramezan, Majid (2013). Examining the impact of knowledge management practices on knowledge-based results. Journal of Knowledge-based Innovation in China, 3(2), 106-118.

4. Seleim, Ahmed A.S. (2011). Understanding the knowledge management-intellectual capital relationship: a two way analysis. Journal of Intellectual Capital, 12(4), 586-614.

5. Liao, Shu-hsien, Wu, Chi-chuan (2009). The Relationship among Knowledge Management, Organizational Learning, and Organizational Performance. International Journal of Business and Management, 4(4), 64-76.

6. Tomah, V.V. (2014). Sutnist' procesu upravlinnya znannyamy pidpryemstv promyslovosti. Problemy ekomomiky, 2, $161-166$. [in Ukrainian]

7. Sherbakov, O.V., Naryshkin, V.S. (2011). Systema pidtrymky pryjnyattya rishen' yak nevid'emna chastyna suchasnogo informacijnogo zabezpechennya dlya upravlinnya biznesom. Informacijni tehnologii v tehnichnyh systemah, 3, 93-96.

8. Bochulya, T.V. (2013). Organizaciya informacijnoyi skladovoyi v ekonomichnomu prostori. Evropejs'kyj vector ekonomichnogo rozvytku, 2, 32-43. [in Ukrainian]

9. Lee, Sangjae (2012). An integrated view of knowledge management for performance. Journal of Knowledge Management, 16(2), 183-203.

10. Ologbo, Andrew C., Khalil Md Nor. (2015). Knowledge Management Processes and Firm Innovation Capability: A Theoretical Model. Asian Social Science, 11(18), 10-17.

11. Levykin, V.M. (2017). Model' bazy znan' informacsjnoyi systemy procesnogo upravlinnya. Visnyk Nac. teh. un-tu "HPI" : zb. nauk. pr. Ser: Systemnyj analiz, upravlinnya ta informacijni yrhnologii, 28(1250), 74-78. [in Ukrainian]

12. Ologbo, Andrew C., Khalil Md Nor. (2015). Knowledge Management: The Way to Organizational Competitive Advantage. Economics of Knowledge, 7(1), 25-35.

13. Inkinen, Henri (2016). Review of empirical research on knowledge management practices and firm performance. Journal of Knowledge Management, 20(2), 230-257. 
14. Storey, Veda C. II-YeolSongb (2017). Big data technologies and Management: What conceptual modeling can do. Data \& Knowledge Engineering, 108, 50-67. [

15. Massaro, Maurizio, Dumay, John, Garlatti, Andrea (2015). Public sector knowledge management: a structured literature review. Journal of Knowledge Management, 19(3), 530-558.

16. Paré, Guy, Trudel, Marie-Claude, Jaana, Mirou, Kitsiou, Spyros (2015). Synthesizing information systems knowledge: A typology of literature reviews. Information \& Management, 52(2), 183-199.

17. Brhel, Manuel, Meth, Hendrik, Maedche, Alexander, Werder, Karl (2015). Exploring principles of user-centered agile software development: A literature review. Information and Software Technology, 61, 163-181.

18. Panetto, Hervé, Zdravkovic, Milan, Jardim-Goncalves, Ricardo, Romero, David, Cecil, J., Mezgár, István (2016). New perspectives for the future interoperable enterprise systems. Computers in Industry, 79, 47-63.

19. Rubalko, L.P. (2015). Zastosuvannya suchasnykh korporatyvnyh infornacijnyh system $v$ upravlinni pidpruemstvamy. Naukovyj visnyk Hersons'kogo derzhavnogo universutetu: zb. nauk. pr. Ser.: Ekonomichni naiky, 15. 82-85. [in Ukrainian]

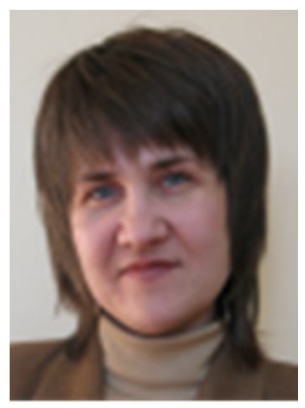

\section{Зміївська Ірина Віталіївна.}

Старший викладач кафедри «Обліку та інформаційних технологій у бізнесі», Харківський торговельно-економічний інститут Київського національного торговельно-економічного університету, пров. О. Яроша, 8, м. Харків, Харківської обл., Україна, 61045.

Тел. +38(067) 9989078 . E-mail: irina.zmievska@gmail.com

\section{Zmiivska Iryna Vitaliivna,}

Senior Lecturer of Accounting and Information Technology in Business Department, Kharkiv Institute of Trade and Economics of Kyiv National University of Trade and Economics, prov. O. Jarosha, 8, Kharkiv, Kharkiv Region, Ukraine, 61045.

Tel. +38(067) 998 9078. E-mail: irina.zmievska@gmail.com

ORCID: http://orcid.org/0000-0002-0774-2272

Researcher ID: http://www.researcherid.com/rid/N-3578-2016

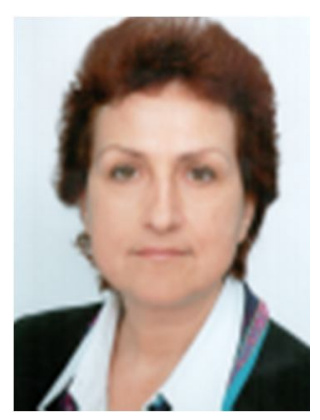

\section{Обоянська Любов Афанасіївна,}

Старший викладач кафедри «Обліку та інформаційних технологій у бізнесі», Харківський торговельно-економічний інститут Київського національного торговельно-економічного університету, пров. О. Яроша, 8, м. Харків, Харківської обл., Україна, 61045. Тел. +38(066) 8449725 . E-mail: L_A_O@ukr.net

\section{Oboianska Liubov Afanasiivna,}

Senior Lecturer of Accounting and Information Technology in Business Department, Kharkiv Institute of Trade and Economics of Kyiv National University of Trade and Economics, prov. O. Jarosha, 8, Kharkiv, Kharkiv Region, Ukraine, 61045. Tel. +38(066) 8449725 . E-mail: L_A_O@ukr.net

ORCID: http://orcid.org/0000-0002-8842-1795

Researcher ID: http://www.researcherid.com/rid/N-3035-2016

Citation (APA):

Zmiivska, l., Oboianska, L. (2019). Information technology knowledge management in business. Engineering and Educational Technologies, 7(3), 98-105. doi: https://doi.org/10.30929/2307-9770.2019.07.03.09

\section{Цитування (ДСТУ 8302:2015):}

Зміївська І. В., Обоянська Л. А. Інформаційні технології управління знаннями у бізнесі / Інженерні та освітні технології. 2019. T. 7. № 3. C. 98-105. doi: https://doi.org/10.30929/2307-9770.2019.07.03.09

Обсяг статmі: $\quad$ сторінок - 8 ; умовних друк. аркушів - 1,159. 